Donald R. Miller MD, Marion Wellwood MB,

Sallie J. Teasdale MD, Daniel Laidley MD, Joan Ivanov RN, Patricia Young RN, Mindy Madonik B SC, Peter McLaughlin MD, Donald A.G. Mickle MD, Richard D. Weisel MD

\section{Effects of anaesthetic induction on myocardial function and metab- olism: a comparison of fentanyl, sufentanil and alfentanil}

Anaesthetic induction may induce myocardial ischaemia in patients with coronary artery disease. "High-dose" fentanyl has become the most widely used technique for induction prior to coronary artery bypass graft (CABG) surgery, since its introduction by Stanley et al. ' in 1978. Although high-dose fentanyl provides haemodynamic stability during induction, it may not adequately prevent the hypertensive response to intubation ${ }^{2,3}$ which has been associated with evidence of myocardial ischaemia. ${ }^{4}$

Sufentanil has recently emerged as a popular anacsthetic drug for coronary bypass surgery. Sufentanil is five to ten times as potent as fentanyl and may prevent the hypertensive response to noxious stimuli occasionally seen with fentanyl. ${ }^{5.6}$ Alfentanil is a fentanyl analogue currently undergoing clinical investigation for use in coronary

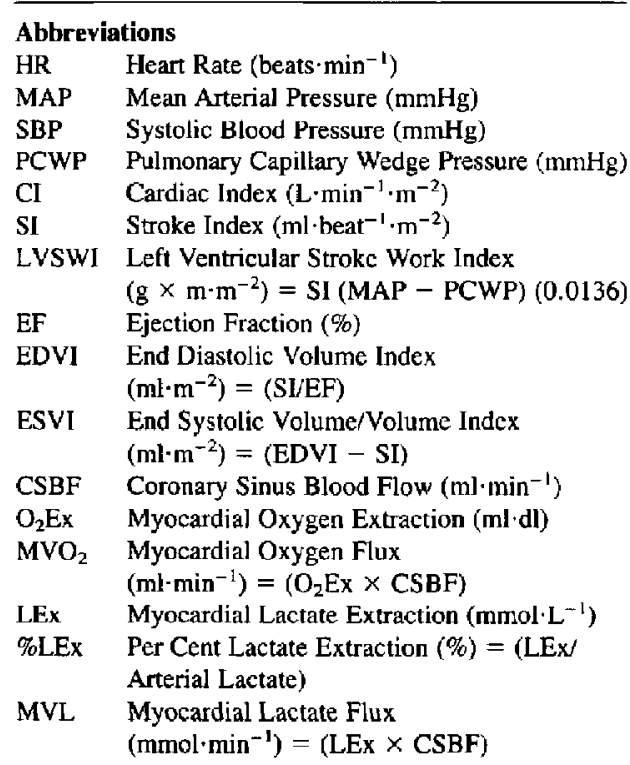


bypass surgery. Alfentanil has one-third to one-fourth the potency of fentanyl, and may limit the postoperative respiratory depression seen with fentanyl because of its short elimination half-life of $1.5 \mathrm{hr} .^{7,8}$

Several studies have reported the successful use of sufentanil and alfentanil in paticnts undergoing coronary bypass and valvular heart surgery ${ }^{5,6,9-11}$ with haemodynamic stability comparable to that during fentanyl anaesthesia. However, preliminary investigation in our institution demonstrated that these drugs may have significant differences in their effects on ventricular function, including alterations of myocardial contractility and diastolic compliance. It was felt reductions in diastolic compliance might reflect ischaemic myocardial metabolism. The purpose of this investigation was to compare the effects of induction with fentanyl, sufentanil or alfentanil on myocardial function and metabolism in a prospective randomized trial of patients undergoing elective CABG surgery.

\section{Methods}

\section{Patient population}

Ninety-six patients scheduled for elective CABG surgery agreed to participate in this trial and gave written informed consent. The trial had been approved by the institutional and the University Human Experimentation Committees. Each patient had two or three vessel coronary artery disease, stable angina pectoris and a preoperative contrast ventriculographic ejection fraction $>40$ per cent. Patients with a history of myocardial infarction within one month of surgery were excluded. Additional patient characteristics are presented in the Table.

\section{Anaesthetic managemett}

Antianginal medications (Table) were continued until the morning of surgery. Patients were premedicated with lorazepam $\left(0.06 \mathrm{mg} \cdot \mathrm{kg}^{-1}\right.$ sublingually) $90 \mathrm{~min}$ prior to the study, morphine $\left(0.15 \mathrm{mg} \cdot \mathrm{kg}^{-1}\right)$ and perphenazine (0.075 $\mathrm{mg} \cdot \mathrm{kg}^{-1}$ ) intramuscularly $60 \mathrm{~min}$ prior to the study. After the initial measurements (described below) anaesthesia was induced with the assigned drug according to the randomization schedule while patients breathed 100 per cent oxygen by mask. Fentanyl $\left(75 \mu \mathrm{g} \cdot \mathrm{kg}^{-1}\right)$ and sufentanil $\left(15 \mu \mathrm{g} \cdot \mathrm{kg}^{-1}\right)$ were administered over 60 seconds while alfentanil $\left(125 \mu \mathrm{g} \cdot \mathrm{kg}^{-1}\right)$ was administered over 60 seconds followed by an infusion of $5.0 \mu \mathrm{g} \cdot \mathrm{kg}^{-1}$. $\mathrm{min}^{-1}$ until completion of the study. A continuous infusion of alfentanil has been recommended in order to stabilize drug concentration with this short-acting agent. ${ }^{12,13}$

Metocurine ( $\left.0.3 \mathrm{mg} \cdot \mathrm{kg}^{-1}\right)$ was used to provide muscle relaxation as this drug although not free of cardiovascular
TABLE Clinical information (mean \pm SD)

\begin{tabular}{lccc}
\hline Preoperative & Fentanyl & Alfentanil & Sufentanil \\
\hline Patients & 31 & 32 & 33 \\
Age (years) & $54 \pm 8$ & $57 \pm 9$ & $54=10$ \\
Sex (M/P) & $31 / 0$ & $30 / 2$ & $32 / 1$ \\
NYHA & $2.9 \pm 0.7$ & $2.8 \pm 0.5$ & $2.5=0.9$ \\
LV grade & $1.5 \pm 0.6$ & $1.6 \pm 0.7$ & $1.4 \pm 0.6$ \\
Diseased vessels & $2.4 \pm 0.8$ & $2.8 \pm 0.5 *$ & $2.9 \pm 0.3^{*}$ \\
SBP (mmHg) & $130 \pm 24$ & $128 \pm 18$ & $130 \pm 20$ \\
DBP & $77=10$ & $78 \pm 11$ & $80 \pm 8$ \\
Beta blockers (\%) & $23(74 \%)$ & $27(84 \%)$ & $23(70 \%)$ \\
Calcium antagonists (\%) & $17(55 \%)$ & $20(63 \%)$ & $19(58 \%)$ \\
& & & \\
Operative & & & \\
Bypasses & $3.2 \pm 1.0$ & $3.7 \pm 1.0$ & $3.7 \pm 0.9$ \\
CPB time (min) & $117 \pm 36$ & $116 \pm 22$ & $131 \pm 29$ \\
Cross-clamp time (min) & $62 \pm 20$ & $62 \pm 19$ & $68 \pm 19$ \\
& & & \\
Postoperative & & & \\
Mortality (\%) & $1(3 \%)$ & 0 & 0 \\
MI (\%) & $1(3.2 \%)$ & $2(6.6 \%)$ & $2(6.5 \%)$ \\
LOS (\%) & $2(6.2 \%)$ & $3(9.9 \%)$ & $2(6.5 \%)$ \\
Pesak CK-MB (units.L-1) & $36 \pm 27$ & $39 \pm 27$ & $38 \pm 23$ \\
\hline
\end{tabular}

"Different from FEN. †From SUF $(p<0.05$ ).

NYHA: New York Heart Associacion; LV: left ventricle; SBP: systolic blood pressure; DBP: diastolic blowd pressure; CBP: cardiopulmanary bypass; MI: myocardial infaretion; LOS: low output syndrome; CK. MB: cardiac isoenzyme of creatine kinase.

side-effects, has been associated with less tachycardia and evidence of myocardial ischaemia compared to pancuronium in patients undergoing $\mathrm{CABG}$ with highdose fentanyl. ${ }^{14}$ All patients were ventilated to normocarbia with 100 per cent oxygen throughout the study. Following completion of the protocol, maintenance anaesthesia was continued with fentanyl and muscle relaxant at the discretion of the attending anaesthetist.

\section{Protocol}

The study sequence is illustrated in Figure 1. Volume loading $\left(\mathrm{VL}_{1}\right)$ studies were performed prior to induction of anaesthesia in order to assess ventricular function. One to two units of stored plasma were rapidly infused to raise the pulmonary capillary wedge pressure (PCWP) 2-4 $\mathrm{mmHg}^{15,16}$ and the haemodynamic and metabolic responses were measured. A colloid solution is necessary to produce the rapid but sustained tises in PCWP and ventricular volume required for comparison of the myocardial function curves. Plasma was chosen for this study as it was in common use perioperatively in our institution at the time. The observers were blinded as to the identity of the study drug but the anaesthetist was not. The initial bolus of drug was diluted to a $50 \mathrm{ml}$ volume and administered via a large syringe. 


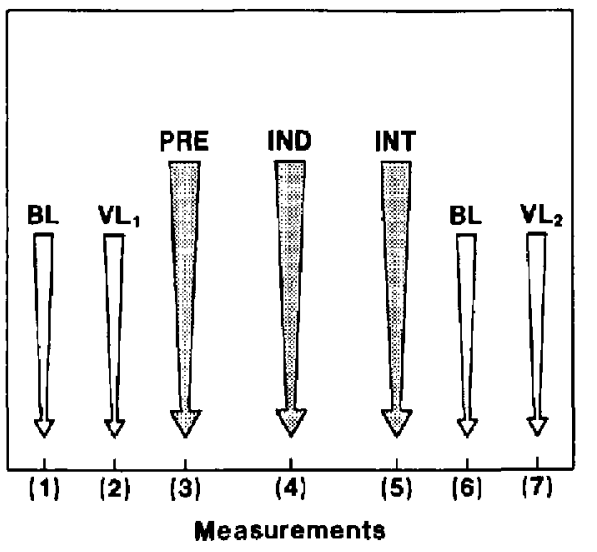

FGURE I Study protocol. The numbers indicate measurement periods. $\mathrm{BL}=$ baseline; $\mathrm{VL}_{1}=$ first volume loading episode; PRE = pre-induction; IND = one minute after induction; INT = one minute after intubation; $\mathrm{BL}=$ baseline; $\mathrm{VL}_{2}=$ second volume loading episode.

Following a five- to ten-minute stabilization period the measurements were repeated (PRE). Then anaesthesia was induced with either fentanyl, sufentanil or alfentanil according to a computer-generated randomization schedule. Measurements were repeated one minute following induction (IND) and again one minute after intubation (INT). Five minutes after intubation another baseline measurement was made and volume loading $\left(\mathrm{VL}_{2}\right)$ was repeated to assess any change in ventricular performance and myocardial metabolism caused by the anaesthetic agents independent of any alterations in preload or afterload. The entire study sequence after initial measurements required $20-25$ minutes. Mean arterial blood pressure $<60 \mathrm{mmHg}$ for more than 30 seconds was treated with a vasopressor, intravenous phenylephrine ( $0.2 \mathrm{mg}$ increments) and calcium chloride $(0.5 \mathrm{gm})$ to restore MAP to $70 \mathrm{mmHg}$.

\section{Measurements}

In the operating room lead $\mathrm{V}_{5}$ of the ECG was monitored continuously at a standardization of $20 \mathrm{~mm} / \mathrm{mV}$. The following catheters were inserted percutaneously with local anaesthesia: radial arterial, pulmonary artery thermodilution and a Ganz* coronary sinus thermodilution catheter. The latter was inserted via the right internal jugular vein into the mid-coronary sinus under tluoroscopic control, aided by the injection of contrast medium.

*Webster Laboratories, Inc, Altadena, Califomia.
Heart rate, systemic and pulmonary artery pressures and pulmonary capillary wedge pressures were measured directly. Cardiac outputs were measured in triplicate with iced five per cent dextrose. Cardiac index and left ventricular stroke work index were calculated using standard formulae.

The double thermistor coronary sinus catheter was inserted in 27 patients, in equal distribution amongst the three groups, to permit blood sampling for $\mathrm{PO}_{2}$, oxygen saturation $\left(\mathrm{HbO}_{2}\right)$ and lactate content measurements. $\dagger$ Oxygen content $\left(\mathrm{CO}_{2}\right)$ was calculated from the haemoglobin (Hb) and $\mathrm{HbO}_{2}$ measurements using the formula:

$\mathrm{CO}_{2}=1.34 \times \mathrm{Hb} \times \mathrm{HbO}_{2}+\left(0.0031 \times \mathrm{PO}_{2}\right)$.

Myocardial oxygen extraction $\left(\mathrm{O}_{2} \mathrm{Ex}\right)$ and myocardial lactate extraction (LEx) were calculated as the difference between the coronary sinus and arterial oxygen and lactate contents.

The coronary sinus catheter was employed to measure coronary sinus blood flow using the continuous thermodilution technique of Ganz et al. ${ }^{17}$ Myocardial oxygen consumption $\left(\mathrm{MVO}_{2}\right)$ and myocardial lactate flux (MVL) were calculated with the formulae:

$$
\begin{aligned}
& \mathrm{MVO}_{2}\left(\mathrm{ml} \cdot \mathrm{min}^{-1}\right)= \operatorname{CSBF}\left(\mathrm{ml} \cdot \mathrm{min}^{-1}\right) \\
& \times \mathrm{O}_{2} \mathrm{Ex}\left(\mathrm{ml} \cdot \mathrm{dl}^{-1}\right) / 100 . \\
& \mathrm{MVL}\left(\mathrm{mmol} \cdot \mathrm{min}^{-1}\right)= \operatorname{CSBF}\left(\mathrm{ml} \cdot \mathrm{min}^{-1}\right) \\
& \times \mathrm{LEx}\left(\mathrm{mmol}^{-1} \mathrm{l}^{-1}\right) / 1000
\end{aligned}
$$

Equilibrium-gated nuclear ventriculograms were performed with a commercially available, non-imaging computerized nuclear probe. $\ddagger^{18,19}$ This portable unit consisted of a $5 \mathrm{~cm}$ diameter thallium activated sodium iodide crystal attached to an $8 \mathrm{~cm}$ converging collimeter. The analogue scintillation data and the ECG were simultaneously sampled at ten millisecond intervals by a microprocessor. The probe was carefully positioned over the precordium and the region of the left ventricular counts was marked on the skin. The intraventricular septum was identified as the area without counts between ventricles. After positioning the probe the patient was not moved and the position was reconfimed prior to the second volume loading episode.

Scintigraphic measurements were performed after the red blood cells were labelled in vivo by infusing $30 \mathrm{mg}$ of stannous pyrophosphate followed 25 minutes later by 9.2 $\times 10^{2} \mathrm{mbq}(25 \mathrm{mCi})$ of Technetium $99 \mathrm{~m}$ pertechnetate. The probe then calculated left ventricular end diastolic counts (FDC) and end-systolic counts (ESC). Left ven-

†Rapid Lactate Stat Pack Kit, Calbiochemical - Behring Company, La Jolla, Califomia.

†Nuclear Stethoscopy, Bros Inc., Aramis NJ, USA. 
tricular ejection fraction (EF) was calculated from the formulae: ${ }^{20}$

$\mathrm{EF}=(\mathrm{EDC}-\mathrm{ESC}) / \mathrm{EDC}$.

The accuracy of the nuclear probe was evaluated in an carlier study at our institution by comparing the results to those obtained with a gamma camera (Technique 420) interfaced with a Digital Equipment Corporation microcomputer. Intertechnician variability was minimal. Measurements of ejection fractions of 26 consecutive patients performed by the two technicians showed a good correlation ( $r=0.887, p<0.01$, line of regression $y=1.0536 x$ - 3.3046). Comparisons of 29 ejection fractions measured by the nuclear probe and by the gamma camera showed a good correlation $(r=0.891, p<0.01$, line of regression $y=1.2668 \mathrm{x}-5.7598){ }^{21}$

The left ventricular end-diastolic volume index (EDVI) was calculated from the thermodilution stroke index divided by the radionuclear ejection fraction.

The propagated error of the calculated end-diastolic volume index incorporated the errors of the scintigraphic and thermodilution measurements. Calvin et al. ${ }^{22}$ suggested that the variation in the thermodilution measurement was approximately nine per cent and that of the nuclear ejection fraction measuremen! was approximately seven per cent. They suggested that the overall variation in the end-diastolic volume calculated approached 12 per cent. This variation was reduced in our study as serial measurements were made in the same patient.

The left ventricular end-systolic volume index was determined from the formula:

$\mathrm{ESVI}=\mathrm{EDVI}-\mathrm{SI}$.

Myocardial performance was assessed by examining the increase in cardiac index per unit increase in PCWP and EDVI induced by volume loading. Left ventricular systolic function was examined by comparing the increase in systolic blood pressure to the increase in ESVI with volume loading. Left ventricular compliance was assessed examining the relationship between PCWP and EDVI.

Statistical analysis was performed using the System for Statistical Analysis Program.* The changes with induction in intubation and volume loading were evaluated by an analysis of variance (ANOVA) using the general linear models procedure. ${ }^{23,24}$ The two main effects shown by ANOVA were anaesthetic sequence and the anaesthetic drug. Separate analysis of variance werc performed to specify difference in the anaesthetic sequence or between drugs when the main effects were independently or interactively significant $(p<0.05$ ). Difference between

*SAS Institute Inc., Box 8000, Cary, N.C. means were also specified using Duncan's multiple range test when the ANOVA was significant $(\mathrm{p}<0.05$ ). Analysis of covariance (ANOCOVA) was used to evaluate myocardial performance, diastolic compliance and systolic function. Chi square and Fisher's exact tests were employed to compare original data. The results are reported as mean and standard error in the figures and mean and standard deviation in the text and tables. Statistical significance was assumed when $\mathrm{p}<0.05$.

\section{Results}

The preoperative characteristics of the patients are presented in the Table. There were no differences between groups except that the patients who received fentanyl had fewer diseased vessels than those who received either alfentanil or sufentanil. The conduct of the operation after anaesthetic induction was identical in the three groups.

Postoperatively, six patients had evidence of a perioperative myocardial infarction (the appearance of a new $Q$ wave), two in each of the groups. Seven patients developed postoperative low output syndrome (the need for inotropic drugs or intra-aortic balloon pump assistance), two in the fentanyl, three in the sufentanil and two in the alfentanil group. One patient in the fentanyl group died, with no deaths in the other two groups. The postoperative results were similar after induction with the three agents.

The haemndynamic and metabolic responses to volume loading for the three groups were similar prior to induction. Therefore, the data $\left(\mathrm{BL}-\mathrm{VL}_{7}\right)$ were combined in Figures 2-4 in order to facilitate comparison of the separate responses to volume loading after induction and intubation $\left(\mathrm{BL}-\mathrm{VL}_{2}\right)$ for each of the three groups as shown in Figures 2 and 3 and as described in the following sections.

\section{Haemodynamic response to induction and intubation}

The haemodynamic responses to the anaesthetic sequence are presented in Figures 2 and 3. Induction produced a significant decrease in systolic, diastolic and mean arterial blood pressure with all three drugs, but alfentanil and sufentanil induced a greater depression than fentanyl $(p<0.05)$. The fall in blood pressure one minute after induction was followed by a progressive decrease in the alfentanil group which persisted for nearly five minutes. Four of the 32 patients (12 per cent) required treatment with calcium and phenylephrine. Ten of the patients ( 30 per cent) had a fall in systolic pressure greater than 30 $\mathrm{mmHg}$, with absolute pressures less than $100 \mathrm{mmHg}$ in seven patients. Only one patient (three per cent) required vasopressors after induction with sufentanil, and no patient developed clinically significant hypotension after induction with fentanyl 

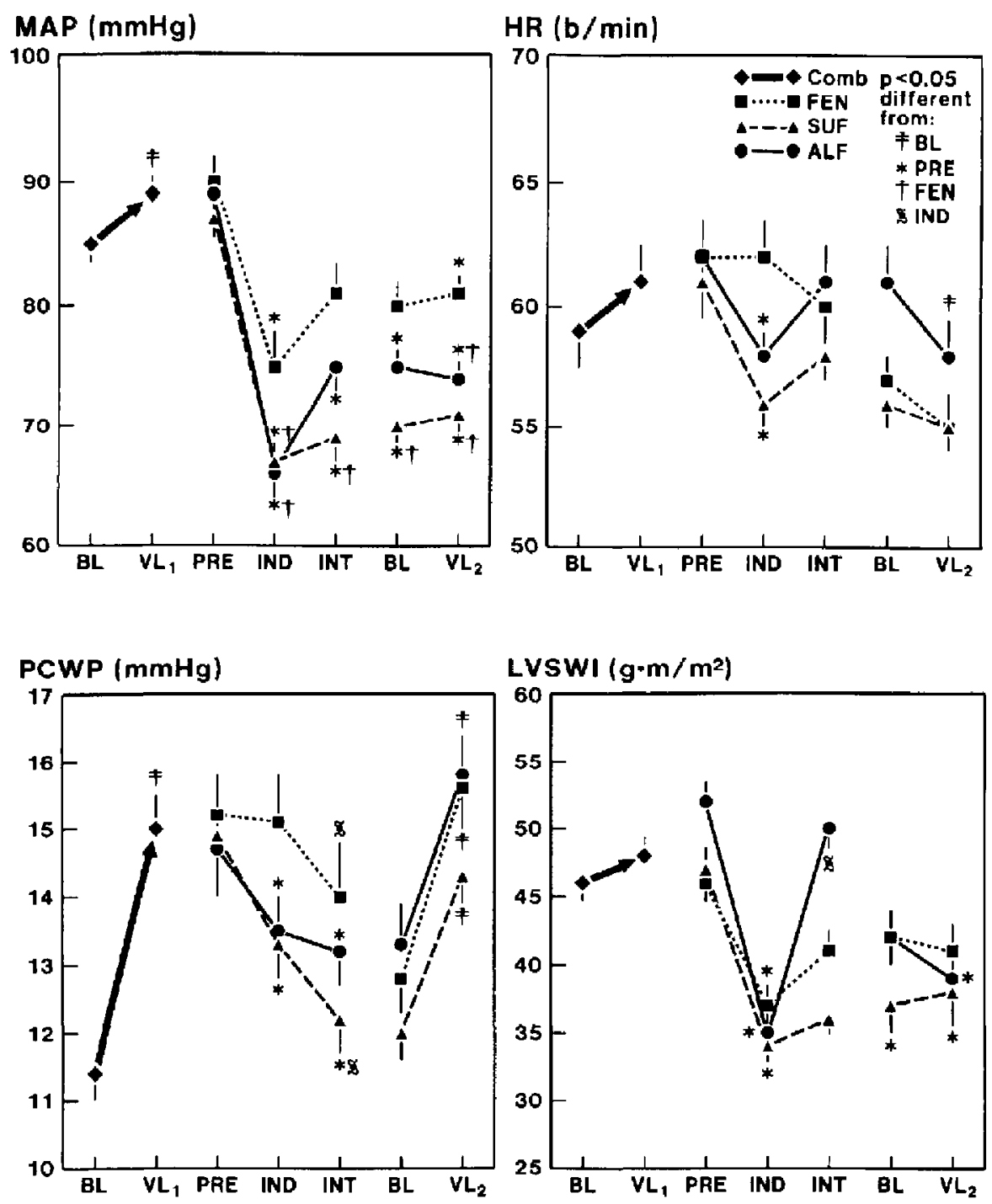

FIGURE 2 The haemodynamic responses to induction (IND), intubation (INT) and volume loading (VL, and $V L_{z}$ ). The responses to volume loading were combined (COMB) prior to IND. An analysis of variance (ANOVA) was employed lo evaluate the anaesthetic sequence and the anaesthetic agents: fentanyl (FEN), sufentanil (SUF) and alfentanil (ALF). Differences were specified when the ANOVA was significant ( $\mathrm{P}<$ 0.05). MAP = mean arrerial pressure; $\mathrm{HR}=$ heart rate; $\mathrm{PCWP}=$ pulmonary capillary wedge pressure; $L V S W 1=$ left ventricular stroke work index. 

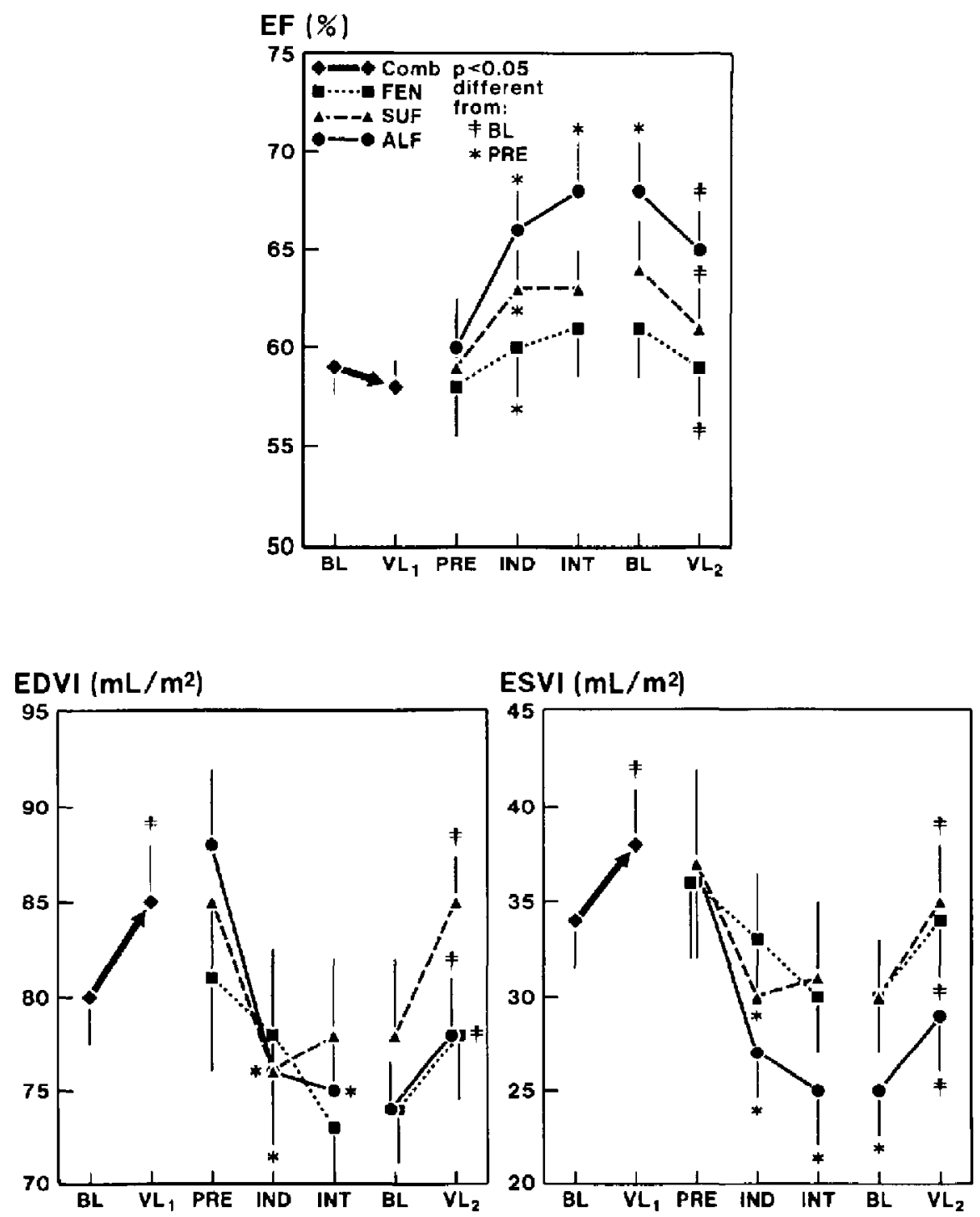

FIGURE 3 The response of the nucleat ventriculographic variables to induction (IND), intubation (INT) and volume loading ( $\mathrm{VL}_{1}$ and $\mathrm{VL}_{2}$ ). The response to volume loading were combined (COMB) prior to IND. An analysis of variance (ANOVA) was employed to evaluate the anaesthetic sequence and the anacsthetic agents: fentany) (FEN), sufentanil (SUF) and alfentanil (ALF). EF = ejection fraction; EDVI = end-diastolic volume index; ESVI = end systolic volume index. 

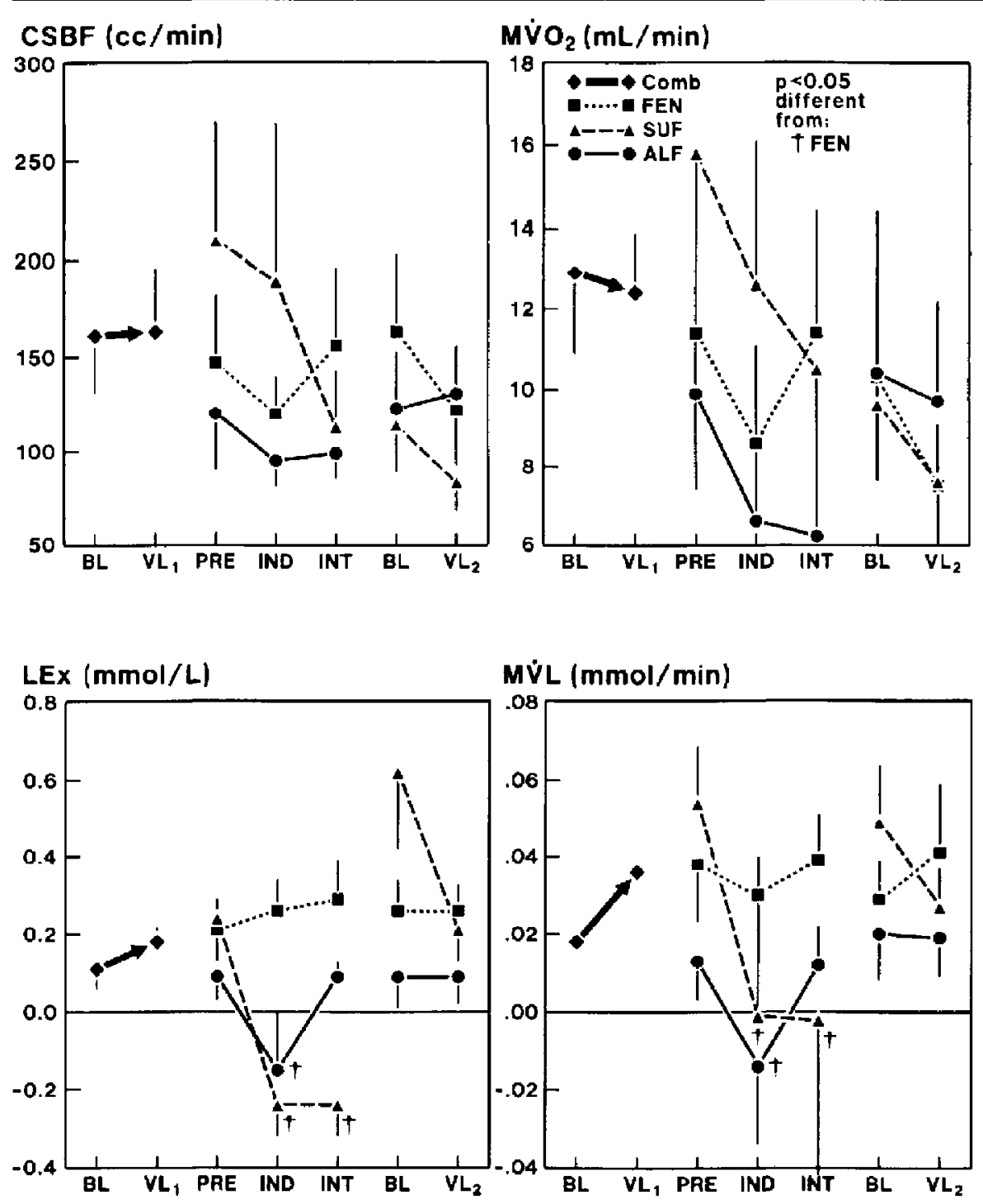

FIGURE 4 The myocardial metabolic response to induction (IND), intubation (INT) and volume loading (VL $L_{1}$ and VL, The responses to volume luading prior to intubation were combined (COMB). An analysis of variance (ANOVA) was employed to evaluate the anacsthctic sequence and the anaesthetic agents: fentanyl (FEN), sufentanil (SUF) and alfentanil (ALF). CSBF $=$ coronary sinus blood flow; $M$ VO $2=$ myocardial oxygen flux; $L E x=$ cardiac lactate extraction; MVL $=$ myocardial lactate flux. 

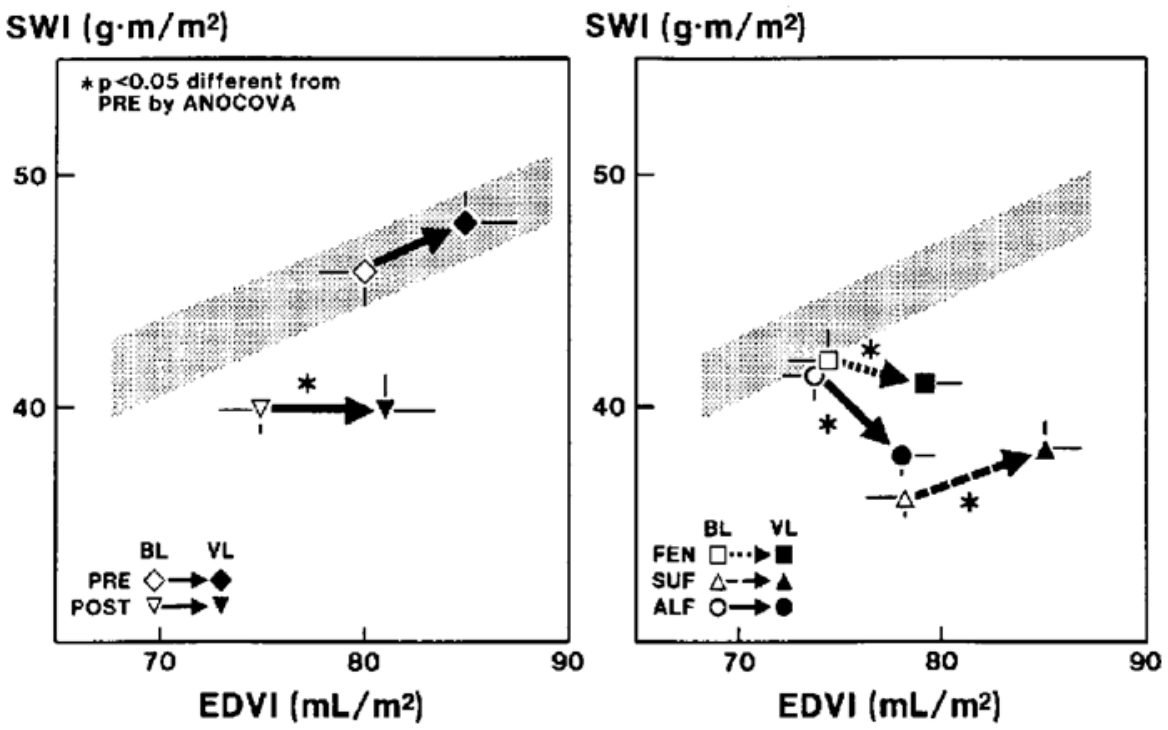

FIGURE 5 Myocardial performance was evaluated as the relation between the stroke work index (SWI) and end-diastolic volume index (EDVI). An analysis of covariance permitted evaluation of the anaesthetic sequence (left panel) and the anaesthetic agents (right panel). The left panel illustrates the combined response to volume loading before induction (PRE, with the 70 per cent confidence limits stippled). The right panel show's the response of the individual drugs to volume loading after intubation (with the 70 per cent confidence limits of the PRE measurements stippled). Fentanyl induced less depression than either sufentanil or alfentanil.

Induction with sufentanil and alfentanil, but not fentanyl, produced small but significant decreases in heart rate (HR) and pulmonary capillary wedge pressure (PCWP). Induction caused a decrease in both cardiac index $(\mathrm{CI})$ and stroke work index (SWI) with all three drugs.

Alfentanil and sufentanil produced corresponding significant $(p<0,05)$ reductions in end-systolic (ESVI) and end-diastolic volume indices (EDVI). with alfentanil causing the greatest reduction. Although induction produced an increase in ejection fraction (EF) with all three drugs ( $p<0.05$ ), the effect was greatest with alfentanil, which caused the greatest decrease in both preload (EDVI) and afterload (MAP).

In spite of the tendency of intubation to increase the MAP in all three groups (not significant), the MAP after intubation in the alfentanil and sufentanil groups remained significantly lower than pre-induction (PRE) MAP values and the rise in MAP with intubation in the sufentanil group was significantly less than the rise in the fentanyl group. The alfentanil group exhibited an increased cardiac and stroke work index without an increase in heart rate. Sufentanil and fentanyl were not associated with any significant changes in these haemodynamic indices during intubation.

Intubation did not restore EDVI, ESVI or ejection fractions in any group.

\section{Metabolic response to induction, intubation and volume} loading

Figure 4 depicts the metabolic responses to induction and intubation. Coronary sinus blood flow and myocardial oxygen consumption were not significantly altered by any of the three narcotics. However, myocardial lactate production (anaerobic myocardial metabolism) was observed in 50 per cent (four of eight) of the alfentanil gronp of patients during induction, and correlated ( $p<0.01$ by ANOCOVA) with the reduction in MAP caused by alfentanil during induction. This response was significantly greater ( $\mathrm{p}<0.05$ by Chi square analysis) than observed with either fentanyl of sufentanil. No patients who received fentanyl, and only one patient of nine who received sufentanil, demonstrated myocardial lactate production.

In response to volume loading, myocardial oxygen 


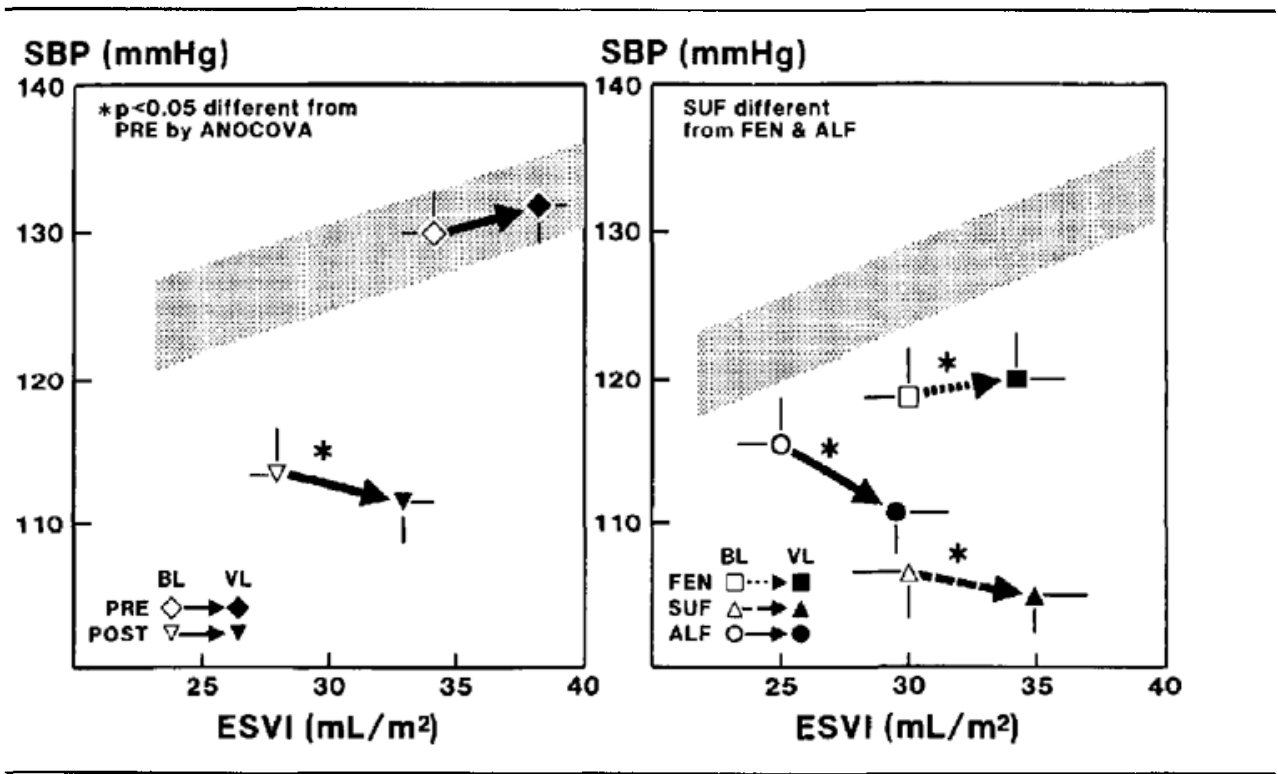

FIGLRE 6 Systolic function as the relation between systolic blood pressure (SBP) and end-systolic volume index (ESVI), An analysis of covariance permitted evaluation of the anaesthetic sequence (left panel) and the anacsthetic agents (right panel). The left panel illustrates the response to volume loading before induction (PRE, with the 70 per cent confidence limits stippled) and after intubation (POST). The right panel shows the individual dng response to volume loading (with the 70 per cent confidence interval of PRE measurements stippled). Sufentanil (SUF) produced a greater depression of systolic function than did alfentanil (ALF) or fentanyl (FEN).

extraction and consumption were not significantly altered for any drug. However, myocardial lactate extraction and flux, which were negative after induction with alfentanil and sufentanil, became positive prior to the second volume loading episode. Volume loading after induction with alfentanil resulted in the lowest myocardial lactate utilization (per cent myocardial lactate extraction: FEN: $28 \pm 24$ per cent; SUF: $23 \pm 20$ per cent; ALF: $6 \pm 16$ per cent; $(\mathrm{p}<0.03)$, suggesting persistent anderobic metabolism following alfentanil induction.

\section{Haemodynamic response to volume loading}

Figure 5 depicts myocardial performance (the relation between SWI and EDVI). On the left, data from the three groups were combined to demonstrate an overall reduction in myocardial performance ( $p<0.01$ by ANOCOVA) after induction and intubation, which describes the effect of the anaesthetic sequence. On the right, the individual responses to volume loading illustrate a depression of performance with all three drugs. Fentanyl caused less depression $(p<0.01)$ than either sufentanil $(p<0.001)$ or alfentanil ( $p<0.001)$.
Figure 6 illustrates that systolic function (the relation between SBP and ESVI) was depressed after induction and intubation ( $p<0.001$ ) by ANOCOVA. Sufentanil caused the greatest depression of systolic function $(p<$ $0.001)$ which was more depressed than with either alfentanil $(p<0.01)$ or fentanyl $(p<0.05)$.

Figure 7 demonstrates the diastolic pressure-volume relations. These were monoxponential in general configuration, and therefore the natural logarithm (ln) of the pulmonary capillary wedge pressures were compared to the end-diastolic volume indices. On the left an overall reduction ( $p<0.05$ by ANOCOVA) in diastolic compliance is demonstrated after induction and intubation. On the right the individual drug responses are depicted. Alfentanil produced the greatest reduction in diastolic compliance which was significantly different from the responses to fentanyl and sufentanil ( $p<0.03$ by ANOCOVA). The patients with the decreased diastolic compliance with alfentanil matched the patients with the ischaemic myocardial lactate production. 

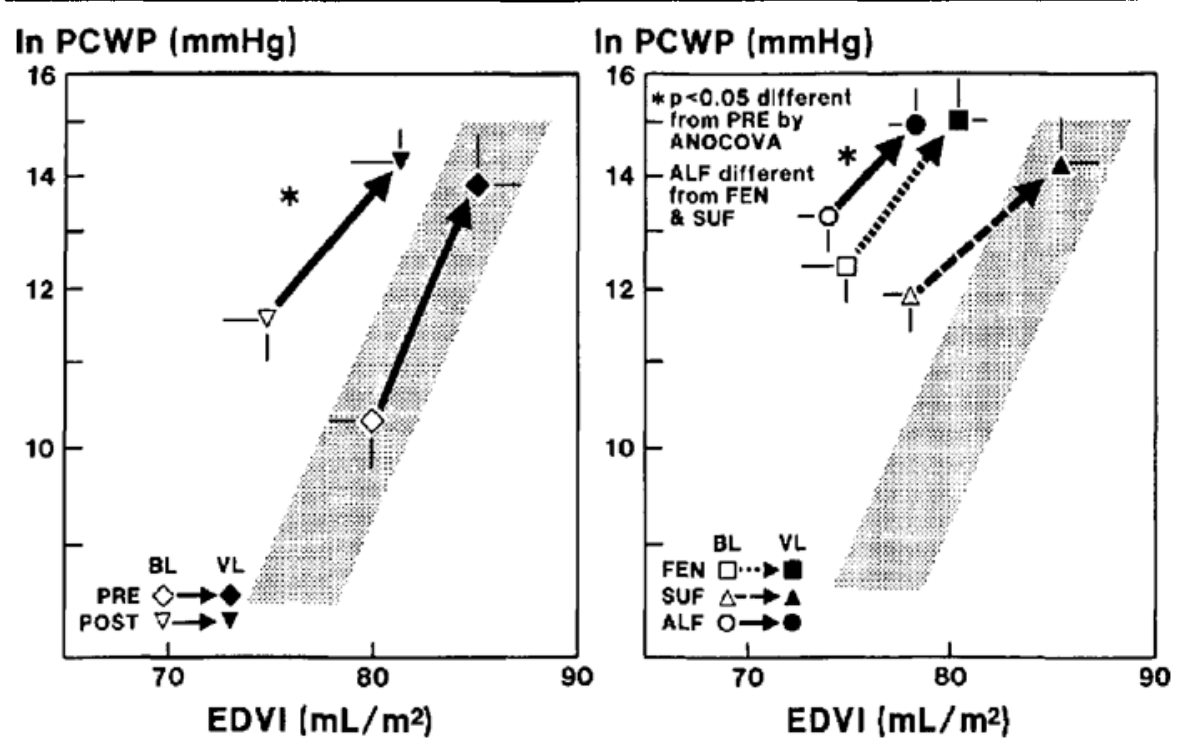

FIGURE 7 Diastolic compliance was evaluated by the diastolic pressure-volume relation. The relation between pulmonary capillary wedge pressurc (PCWP) and and-diastolis volume index were monoexponential and therefore the natural logarithmic (ln) of the PCWP was employcd. An analysis of covariance permitted evaluation of the anaesthetic sequence (left panel) and the anaesthetic agents (right panel). The left panel demonstrates a decrease in diastolic compliance after intubation (POSI) compared to before induction (PRE- with the 70 per cent confidence limits stippled). Alfentanil (ALF, right panel) produecd a greater decrease in diastolic compliance than fentanyl (FEN] or sufentanil (SUF) $>$.

\section{Discussion}

The ideal anaesthetic for patients with significant coronary artery disease should provide adequate anaesthetic depth to abolish the sympathetic responses to surgical stresses. However, the ideal anaesthetic for patients with poor ventricular function should producc minimal depression of myocardial function and preserve cardiac performancc. A short-acting agent that limits postoperative respiratory depression might reduce the time in the intensive care unit and allow an earlier assessment of neurologic integrity. The recently introduced fentanyl analogue alfentanil is a short-acting agent which permits early awakening and early extubation postoperatively. Sufentanil, with its greater potency, has been shown to prevent the haemodynamic responses to noxious stimuli. The advantages of each agent must, however, be weighed against their effects on myocardial performance and metabolism.

\section{Assessment of ventricular furction}

Measurements of mean arterial pressure, pulmonary capillary wedge pressure and cardiac index are important clinical indices, but provide insensitive estimates of ventricular function. Left ventricular ejections fraction measurements provide additional information, but are very sensitive to changes in preload and afterload. Ventricular volumes are required to assess myocardial performance, systolic function and diastolic compliance and compare the response to fentanyl, sufentanil and alfentanil induction.

Echocardiography provides excellent resolution of a limited portion of the ventricle and permits an assessment of regional wall motion abnormalities. However, extrapolations to global ventricular volumes may be difficult in patients with regional wall motion abnormalities. Therefore, echocardiography may provide inaccurate estimates of ejection fraction or ventricular volumes in patients with coronary artery disease. Transoesophageal positioning of the echocardiographic probe limits evaluation of the left ventricle to cross-sectional views, reducing the accuracy of ventricular volume calculations.

We employed gated nuclear ventriculography to provide a noninvasive assessment of ventricular volume which avoided the geometric assumptions required by echocardiography. The nuclear probe provided reproducible ejection fraction determinations and permitted an 
accurate assessment of interventions performed serially in the same patients. The calculation of yentricular volumes permitted an assessment of preload and systolic function.

Sagawa et al. ${ }^{25}$ demonstrated that the end-systolic pressure-volume relation was linear and the slope (E max) reflected left ventricular inotropy in isolated heart preparations using a time-varying systolic elastance model. Grossman $^{26}$ measured end-systolic pressures and volumes in humans before and after a phenylephrine infusion to calculate $\mathbf{E}$ max. However, in patients the increase in arterial pressure with phenylephrine was usually insufficient to accurately calculate $\mathrm{E}$ max. Sagawa et al ${ }^{25}$ have demonstrated that the volume at zero pressure $\left(\mathrm{V}_{0}\right)$ varies over a narrow range. Therefore, a significant increase in end-systolic volume at lower end-systolic pressure implies either a decrease in $E$ max or an increase in $V_{0}$. Sagawa ${ }^{27}$ demonstrated that depressed contractility was associated with both a decreased $E$ max and an increased $V_{0}$. We employed volume loading to provide two end-systolic measurements at different end-systolic pressures and volumes. However, volume loading (like the phenylephrine infusion) did not increase arterial pressure enough to permit the calculation of $\mathrm{E} \max$. As we could, therefore, only evaluate a limited portion of the systolic pressure relation, we employed an analysis of covariance to compare simultaneously the end-systolic pressures and volumes in the three trcatment groups. Differences in these measurements are believed to represent either differences in the slope and/or the volume intercept of the end-systolic relation, both of which may represent depressed contractility. McKay ${ }^{28}$ and Aroesty ${ }^{29}$ found that volume loading was as effective as a phenylephrine infusion to evaluate the end-systolic pressure-volume relationship in patients. They also demonstrated that differences in end-systolic pressures and volumes measured over a narrow range permitted an accurate assessment of systolic function.

The left ventricular diastolic pressure-volume relation was believed to be monoexponential in general configura$\operatorname{tion}^{30}$ and therefore the natural logarithm (ln) of the wedge pressure was calculated and plotted against the end-diastolic volume index ${ }^{22.31}$ to provide a linear relation and permit an assessment of diastolic compliance. We have previously demonstrated that a decrease in the diastolic pressure-volume relation was associated with ischaemic anaerobic myocardial metabolism postoperatively. ${ }^{31,32}$

Myocardial performance was evaluated by examining the relation between left ventricular stroke work index and end-diastolic volume index. Recent experimental studies have demonstrated that "preload recruitable stroke work" provided an estimate of myocardial contractility which was better than the systolic pressure-volume relation. ${ }^{33}$
We used an arithmetic estimate of stroke work rather than a direct measurement although volume loading permits the best evaluation of "preload recruitable stroke work" and ventricular contractility when ventricular pressurevolume loops are measured directly.

\section{Effects of fentanyl, sufentanil and aifentanil on \\ haemodynamics and ventricular function}

All three narcotics decreased afterload (MAP) but only alfentanil produced progressive hypotension which required calcium chloride and vasopressors. A transient decrease of systolic blood pressure (more than $25 \mathrm{mmHg}$ ) has been observed in 40 per cent of patients without coronary artery disease immediately after induction with $150 \mu \mathrm{g} \cdot \mathrm{kg}^{-1}$ of alfentanil. ${ }^{34}$ However, progressive hypotension has not been reported in several earlier investigations in cardiac patients with alfentanil. ${ }^{9-11}$ Prevention of hypotension may have been the result of a slower rate of infusion in one study ${ }^{9}$ in which the same dose of alfentanil (125 $\mu \mathrm{g} \cdot \mathrm{kg}^{-1}$ ) produced only a slight, nonsignificant reduction in mean arterial pressure when the drug was administered over one to two minutes. The hypotension caused by alfentanil in our study was an adverse response which correlated with ischaemic myocardial metabolism. The reduction in blood pressure with fentanyl and sufentanil, however, was not clinically significant in all but one patient in the sufcntanil group. The hypotensive effect of alfentanil may have been, in part, a result of the relatively smaller apparent volume of distribution (Vo) of alfentanil compared to fentanyl or sufentanil. ${ }^{8}$ The smaller VD may have resulted in higher initial plasma concentrations of alfentanil and may account for potency differences based upon bolus versus steady-state measutement, in spite of following our loading dose of alfentanil with a continuous infusion. An additional factor which can explain the hypotension with alfentanil is that this drug has less time lag between serum concentration changes and changes in effect compared to fentanyl. ${ }^{35}$

The hyperdynamic response to intubation was completely prevented by sufentanil, partially prevented by fentanyl and least prevented by alfentanil. Previous investigators have also found that sufentanil moderated the response to surgical stimuli more than did fentanyl. 5,6

Ejection fractions increased during induction with all three drugs, with further increases during intubation in response to alfentanil. The greater rise in ejection fraction with alfentanil can be accounted for by the grcater reduction in afterload (MAP) seen with this drug. However, systolic function was depressed with all three narcotics, despite increases in ejection fraction. This demonstrates the limited usefulness of the latter measurement as an independent index of ventricular function.

Calculation of ventricular volumes was essential in 
order to account for the changes in preload and afterload. In this way we have been able to demonstrate that all three narcotics, in induction doses, depress contractility. Sufentanil caused the greatest depression of systolic function, and fentanyl the least. Despite the depression in systolic function sufentanil did not produce hacmodynamic instability. However, our data suggest that sufentanil should be used more cautiously in patients with impaired ventricular function, and that fentanyl may be the preferred agent for such patients since it depresses systolic function least. This conclusion may be tempered by consideration of the dose ratio of 5:1 fentanyl to sufentanil used in our study. Although the relative potency of sufentanil in humans is not known, the ratio of $5-10: 1$ is now generally accepted and our dose of fentanyl may be slightly less potent than our dose of sufentanil.

The anaesthetic sequence reduced diastolic compliance. The decrease in diastolic compliance may have represented myocardial ischaemia. This change in compliance is also known to render the pulmonary capillary wedge pressure an insensitive predictor of changes in preload (end-diastolic volume index). Following induction, a depression of cardiac indices may have reflected inadequate volume expansion. In addition, volume loading used to restore cardiac index in the noncompliant ventricle may produce excessive rises in left ventricular filling pressures. It has been shown that high filling pressures may impair coronary blood flow to the subendocardium, increasing cardiac ischacmia. ${ }^{36}$ Alfentanil produced the greatest decrease in diastolic compliance which may have induced further ischaemia, and could account for the persistently low myocardial lactate utilization which we observed with this drug following intubation.

\section{Myocardial metabolic measurements}

We measured coronary sinus blood flow with the continuous thermodilution technique described by Ganz et al. ${ }^{17}$ We found a wide variation in these measurements, but the method appeared to be reproducible. The technique measured global, but not regional, coronary blood flow. In patients with coronary artery disease, blood flow limitations are usually regional rather than global. ${ }^{37}$ We have therefore employed the measurement of myocardial lactate extraction to assess cardiac ischaemia. Gertz et at. ${ }^{38}$ demonstrated that a decrease in myocardial lactate extraction to very low levels represented ischaemic lactate production from poorly perfused regions and lactate extraction from well perfused regions in patients with coronary artery disease. Therefore myocardial lactate utilization was employed to reflect heterogeneous cardiac ischaemia. Myocardial lactate production reflects inadequate oxygen delivery for oxygen demands and may indicate abnormalities which may herald progressive ischaemic injury

\section{Effects of tentanyl, sufentanil and alfentanil on myo- cardial metabolism}

Fentanyl induction did not significantly alter coronary sinus blood flow, myocardial oxygen consumption or lactate utilization. Previous investigators have also demonstrated stable myocardial metabolism with fentanyl. . $^{4.39 .40}$ In response to intubation with fentanyl, Sonntag $e t a l .^{4}$ found that five of nine patients had myocardial lactate production. However, their patients had antiangial medications (except pindolol) discontinued 48 hours prior to their study and they received a light premedication (diazepam $10 \mathrm{mg}$ ). In addition, intubation was performed after patients had received only $10 \mu \mathrm{g} \cdot \mathrm{kg}^{-1}$ of fentanyl. Moffitt et al. ${ }^{39}$ demonstrated as have we that induction with large doses of fentanyl $\left(75 \mu \mathrm{g} \cdot \mathrm{kg}^{-1}\right)$ provided stable haemodynamics and myocardial metabolism during intubation. However, snrgical stimulation may induce a hyperdynamic response after fentanyl induction and anaesthetic supplements or antihypertensives may be required to control the autonomic response.

Induction with sufentanil resulted in net myocardial lactate production, without altering oxygen demands. Significantly, the data demonstrated that myocardial lactate extraction and lactate flux remained positive during the induction-intubation sequence in all but one patient in this group. This patient became hypotensive on induction and developed ischaemic ECG changes which were associated with high levels of lactate production (LEx: $-5.6 \mathrm{mmol} \cdot \mathrm{l}^{-1}$ ). These changes corrected to normal values with restoration of blood pressure, but had an effect to cause overall ischaemic myocardial metabolism in this group of patients. However, no other patient in the sufentanil group demonstrated ischaemic metabolism during the study. This one patient appeared to have an atypical response to the sufentanil induction sequence, as the efficiency of myocardial metabolism otherwise appears to be preserved with this drug.

Induction with alfentanil, however, dramatically reduced myocardial lactate utilization and half of the patients demonstrated myocardial lactate production suggesting ischaemic anaerobic metabolism. The ischaemic metabolism could have resulted from mitochondrial dysfunction probably associated with an inequality between supply and demand. There are two possible explanations for this ischaemic metabolism in the presence of no change in total coronary sinus flow. The hypotension produced by alfentanil may have resulted in reduced coronary perfusion pressure and thus reduced coronary blood flow to poorly perfused regions distal to arterial coronary stenoses, or the vasodilating effect of 
alfentanil may actually have facilitated a "coronary steal" phenomenon with blood being diverted away from ischaemic areas.

The patients who received $\mathrm{CaCl}_{2}$ and/or vasopressors after induction required this resuscitation after the completion of the induction measurements. These patients were included in the data for later events. However, the effect of the passage of time in this study was for the lactate extraction to improve and the effect of a rise in blood pressure was for the lactate extraction to improve; consequently, the effect of improved blood pressure should have minimized the negative metabolic effect of the drug.

After induction with alfentanil, intubation produced a hyperdynamic adrenergic response, and 25 per cent of patients continued to produce lactate. Alfentanil in the dosage we employed produced a significant incidence of ischaemic myocardial metabolism in patients with coronary artery disease. The ischaemia was associated with haemodynamic instability and decreased diastolic compliance. Therefore we suggest that alfentanil should not be used as a primary induction agent in most patients with coronary artery disease. The pharmacokinetics of this drug suggest its potential advantages when used as a continuous infusion for maintenance anaesthesia during cardiac surgery. Avoiding sudden increases in plasma levels (as may occur with induction) might avoid the adverse responses we have demonstrated.

\section{Limitations of current investigation}

We have employed very sensitive techniques in this study to show some important differences between fcntanyl, sufentanil and alfentanil, using induction doses that have been found previously to produce satisfactory haemodynamic stability in premedicated cardiac patients. One limitation of this study is that we have not correlated our findings with pharmacokinetic data. Thus, changes in plasma concentration during the study for each drug, and the differing ratio between drugs were not measured. Also, we used equipotent doses of fentanyl and sufentanil (a 1:5 ratio based on EEG criteria) ${ }^{41}$ but the relative dose of alfentanil was approximately one half to one third the fentanyl dose. The alfentanil dose we selected was based on recommendations from previous studies ${ }^{10,11}$ and our own observations that higher doses can produce greater haemodynamic instability. Therefore, our models were used to comparc the effects of these narcotics when administered in clinically relevant induction doses.

We also considered that the choice of premedication and muscle relaxant would have an interactive effect on the cardiovascular responses seen with these narcotics. However, we did not believe it to be appropriate or even ethical to avoid premedicating cardiac patients prior to major surgery. Additionally, muscle relaxants are necessary in order to prevent muscle rigidity with high-dose narcotic analgesia. Randomization and the large number of patients in our investigation produced study groups comparable with respect to these factors, and ensured the validity of our statistical tests.

We conclude that for patients undergoing coronary bypass surgery, fentanyl and sufentanil provide hacmodynamic stability while preserving the efficiency of myocardial metabolism. However, sufentanil in this dose induces a greater depression of myocardial contractility, which suggests that it should be used cautiously in patients with impaired ventricular function. Finally, induction with alfentanil in cardiac patients can produce significant haemodynamic instability and ischaemic anaetobic myocardial metabolism.

\section{Acknowledgements}

The authors would like to thank Ms Yasmin Jwraz, R.T.(N.M.) and Dr. Sylvain Houle for nuclear data acquisition and analysis, and Ms Evelyn Henderson and Ms Sylvie Galipeau for preparation of the manuscript. The authors thank Janssen Laboratories for purchase of the coronary sinus catheters used in the study. The authors also wish to thank the physicians and nurses in the cardiac operating room at Toronto General Hospital whose assistance and patience permitted these studies.

\section{References}

1 Starley $T H$, Webster $L R$. Anesthetic requircments and cardiovascular effects of fentanyl-oxygen and fentanyldiazepam-oxygen anesthesia in man. Anesth Analg 1978; 57: 411-6.

2 Stanley $T H$, Philbin $D M$, Coggins $C H$. Fentanyl-oxygen anaesthesia for coronary artery surgery; cardiovascular and antidiuretic hormone responses. Can Anaesth Soc J 1979; 26: 168-72,

3 Waller J, Hug C, Nagle D, Craver J. Hemodynamic changes during fentanyl-oxygen anesthesia for aortocoronary bypass surgery. Anesthesiology $1981 ; 55: 212-7$.

4 Sonntag $H$, Larsen $R$, Hitfiker $O$, Kettler D, Brockschnieder $B$. Myocardial blood flow and oxygen consumption during high dose fentanyl anesthesia in patients with coronary anery disease. Anesthesiology 1982; 56: 417-22.

5 de Lange S, Boscae MJ, Stanley TH, Pace N. Comparison of sufentanil- $\mathrm{O}_{2}$ and fentanyl $-\mathrm{O}_{2}$ for coronary artery surgery. Anesthesiology 1982, 56: 112-8.

6 Sebel PS, Bovill JG. Cardiovascular effects of sufentanil anesthesia. Anesth Analg 1982; 61: 115-9.

7 Bower S, Hull CJ. Comparative pharmacokinetics of fentanyl and alfentanil. Br J Anaesth 1982; 54: 871-7. 
8 Camu F, Gepts E, Rucquoi $M$, Heykants $J$, Pharmacokinetics of alfentanil in man. Anesth Analg 1982; 61: 657-61.

9 de Lange S, Stanley TH, Bascoe MJ. Alfentanil-oxygen anaesthesia for cornnary artery surgery. $\mathrm{Br} J$ Anaesth 1981; 53: 1291-6.

10 Sebel PS, Bovitl JG, Van der Haven A. Cardiovascular effects of alfentanil anaesthesia. Br J Anaesth 1982; 54 : $1185-90$.

11 Bovill JG, Warren PJ. Schuller JL, Van Wezel HB, Hoeneveld $H M$. Comparison of fentany], sufentanil and alfentanil anesthesia in patients undergoing valvular heart surgery. Anesth Analg 1984; 63: 1081-6.

12 de Lange $S$, de Briujin N. Stanley TH, Bascoe MJ. Alfentanil-oxygen anesthesia: comparison of continuous infusion and frequent bolus techniques for coronary artery surgery. Anesthesinlogy 1981;55: A42.

13. White $P F$, Coe $V$, Shafer A, Sung $M-L$. Comparison of alfentanil with fentanyl for outpatient anesthesia. Anesthesiology 1986; 64: 100-6.

14 Thomson IR, Putnins $C L$. Adverse effects of pancuronium during high-dose fentanyl anesthesia for coronary artery bypass grafting. Anesthesiology 1985; 62: 708-13

15 Weisel RD, Burns RJ. Baird RJ. Optimal postoperative volume loading. J Thorac Cardiovasc Surg 1983; 85 552-63.

16 Weisel RD, Burns RI, Baird RI et al. A comparison of volume loading and atrial pacing following aortocoronary bypass. Ann Thorac Surg 1983; 36: 332-44.

17 Gane W, Tamura K, Marcus HS, Donoso R, Yoshida S, Swan $H$. Measurement of coronary sinus blood flow by continuous thermodilution in man. Circulation 1971; 44: 181-95.

18 Wagner HN Jr, Wake R, Nickoloff E, Nataragjan $T K$. The nuclear stethoscope: a simple device for generation of left ventricular volume curves. Am J Cardiol 1976; 38: 747-50.

19 Wagner HN Jr, Rigo P, Baxter RH, Alderson PO, Douglas $K H$, Housholder $D F$. Monitoring ventricular function at rest and during exercise with a nonimaging nuclear detector. An J Cardiul 1979; 43: 975-9.

20 Burow RD, Strauss $H W$, Singleton $R$. et al. Analysis of left ventricular function from multiple gated acquisition cardiac blood pool imaging. Comparison to contrast angiography. Circulation 1977; 56: 1024-8.

$21 \mathrm{McLaughlin} P R$. Comparison of ejection fractions obtained by nuclear probe versus gamma camera. Unpublished data, Toronto General Hospital.

22 Calvin JE, Driedger AA, Sibbald WJ. Does the pulmonary capillary wedge pressure predict left ventricular preload in critically ill patients? Crit Care Med 1981; 9: 437-43.

23 Ray AA, Sall JP, Salter $M$. SAS User's guide: Statistics, 1982. Cary, NC; SAS Institute Inc., 1982.
24 Goodnight JH, Sall JP, Sarle WS. The GLM Procedure, SAS User's Guide. Statistics AA Ray, JP Sal!, J Safter (eds), Cary, NC., 1982 SAS Institute Inc., 139-99.

25 Sagawa $K$, Sauga $H$, Shoukas A, Bakalar $K$. End-systolic pressure/volume ration: a new index of ventricular contractility. Am J Cardiol 1977; 40: 748-53.

26 Grossman W, Braunwald E, Mann T, McLourin L, Green $L$. Contractile state of the left ventricle in man as evaluated from end-systolic pressure-volume relations, Circulation 1977; 56: 845-52.

27 Sagawa $K$. The end-systolic pressure-volume relation of the ventricle. Definition, modifications and clinical bases (editorial). Circulation 1981; 63: 1223-7.

28 McKay RG, Aroesty JM, Heller GV, Royal HD, Warren $S E$. Grossman $W$. Assessment of the end-systolic pressurevolume relationship in human beings with the use of a timevarying elastance model. Circulation 1986; 74: 97-104

29 Aroesty $J M, M c K a y$ RG, Heller GV, Royal HD, Alo AV, Grossman W. Simultaneous assessment of left ventricular systolic and diastolic dysfunction during pacinginduced ischemia. Circulation 1985; 71: 889-900.

30 Gaasch WH, Levine HJ, Quinones MA, Alesxander $J K$. Left ventricular compliance: mechanisms and clinical implications. Am J Cardiol 1976; 38: 645-53.

31 Fremes $S E$. Weisel RD. Baird RJ et al. Effects of postoperative hypertension and its treatment. J Thorac Cardiovasc Surg 1983; 86: 47-56.

32 Fremes $S E$, Weisel $R D$, Mickle DAG et al. Myocardial metabolism and ventricular function following cold potassium cardioplegia. J Thorac Cardiovasc Surg 1985; 89: 531-46.

33 Glower DD, Spratt JA, Snow ND et al. Linearity of the Frank-Starling relationship in the intact heart: the concept of preload recruitable stroke work. Circulation 1985; 71: 994-1009.

34 Ausems $M$, Hug C, Slanski D, Busm A. Plasma concentrations of alfentanil required to supplement ritrous oxide anesthesia for general surgery. Anesthesiology 1986; 65 : 362-73.

35 Scot J Ponganis K, Stanski D. EEG quantitation of narcotic effect: the comparative pharmacodynamics of fentanyl and alfentanil. Anesthesiology 1985; 62: 234-41.

36 Ellis AK, Kloche FJ. Effects of preload on transmural distribution of perfusion and pressure-flow relationships in the canine coronary vascular bed. Circ Res 1980; 46: 68-77.

37 Sethna DH, Moffitt EA. An appreciation of the coronary circulation. Anesth Analg 1986; 65: 294-305.

38 Gertz EW, Wisteski JA, Neese R, Bistow J, Searle G, Hanlon J. Myocardial lactate metabolism: evidence of luctate release during net chemical extraction in man. 1981; 63: $1273-8$. 
39 Moffit EA, Scovil JE, Barker RA et al. Myocardial metabolism and haemodynamic responses during high-dose fentanyl anaesthesia for coronary patients. Can Anaesth Soc J 1984; 31: 611-8.

40 Skourtis CT, Nissin M, McGinnis LA et al. The effect of high-dose fentanyl on cardiac metabolic balance and coronary circulation in patients undergoing coronary artery surgery (Abstract). Anesthesiology 1984; 61: A6.

41 Sanford TJ, Ty Smith N, Dec-Silver $H$, Harrison W. A comparison of morphine, fentanyl and sufentanil anesthesia for cardiac surgery: induction, emergence and extuhation. Anesth Analg 1986; 65: 259-66.

\section{Résumé}

L'induction de lanesthésie peut induire de I'ischémie myocardique. Une étude prospective randomisée a été conduite afin de comparer l' effet sur la fonction ventriculaire et le métabolisme myocardique de l'induction avec le fentanyl (FEN) ou son analogue sufentanil (SUF) oul' alfentanil (ALF) chez 96 patients devant subir une chirurgie de pontage aorto coronarien élective. Des mesures hémodyrumiques, métaboliques (exaraction de lactate d'oxyène du sinus coronaire) ainsi que des mesures de la fonction ventriculaire par des méthodes nucléaires étaient faites avant I' induction (PRE), aprés l'induction (IND) et après l'intubation (INT). L'induction était faite avec du fentanyl 75 $\mu \mathrm{g} \cdot \mathrm{kg}^{-1}$, suffentanil $15 \mathrm{\mu g} \cdot \mathrm{kg}^{-1}$ et fentanil $125 \mu \mathrm{g} \cdot \mathrm{kg}^{-1}$ associé à la métocurine. L'induction avec le fentanyt a amené la plus grande stabilité de la pression arsérielle moyenne (MAP), la performance cardiaque, et la fonction systolique sans produc tion de lactate par le myocarde. Le sufentanil a produit la plus grande dépression de la fonction systolique ( $p<0.05$ ) sans instabilité hémodynamique ou production de lactate par le myocarde chez tous les patients sauf un. L'induction avec l'alfentanil a produit la plus grande réduction de la pression artérielle moyenne $(p<0.05$ ) associé avec la plus grande diminution de la compliance diastolique $(p<0.05)$ et 50 pour cent d' incidence de production de lactate por le mvocarde $(p<$ 0.05 ) sans changement significatif dans le flot sanguin coronarien ou dans la consommation d'axygène du myocarde. 